\title{
Discussion on Improving the Leadership and Execution of Management Departments in Small and Medium-sized Enterprises
}

\author{
Weixin Liu \\ Guangzhou Huali Science and Technology Vocational College, Guangzhou 510000, China \\ 353508128@qq.com
}

Keywords: Small and medium-sized enterprises; Management department; Leadership; Executive power; Strategic decision

\begin{abstract}
Based on the analysis of the leadership and execution of managers in SME management departments, the paper proposes that the management department has four roles in strategic decision making, which is divided into decision-making participants, strategy executors, messaging and communicators, and strategic executive monitors. Through the empirical analysis on the skills requirements of the management department staff, the determinants of their leadership and execution are divided into education background, management work experience and personal traits. The difference and relevance of force and execution in different types of medium-efficiency enterprises, combined with the academic background, management work experience and personal traits, and the construction of SME management department leadership and execution skills model are explained.
\end{abstract}

\section{Introduction}

In the management work, the management department or leadership members of small and medium-sized enterprises often become an important backbone of policy implementation and implementation in the organization. Through their understanding of superior management strategies, leaders and cadres fully understand the strategic intentions of upper-level leaders and decision-makers, and through their own transformation capabilities, correctly understand and scientifically implement superior strategies [1]. At the same time, management needs to have sufficient action. It must be enthusiasm and initiative for organizational operation and strategy implementation. Therefore, the leadership, transformation and mobility of leadership and management are particularly important. In particular, the leader not only needs to transform the intention of the higher-level decision-making layer into his own thoughts and implementation ideas, but also needs to integrate his own ideas, management styles and strategic experiences into the specific work implementation and command coordination. All in all, management, decision-making and executives, and leaders always have to be at the decision-making level for strategy implementation [2]. Modern enterprises and modern organizations emphasize the new management concept of people-oriented management, and the management work is more humane. Therefore, in 
terms of management, it gradually emphasizes the humanistic concept in strategy execution, and the implementation of strategy is more dependent on the human-centered strategy implementation system and standards.

\section{Theoretical overview}

\subsection{Management Department Role}

According to the reference and the reference of the company information, this paper defines the role of the management department, that is, a staff member has several direct subordinates. Their success or failure directly affects the success or failure of the company's strategy, and the success of the company's decision-making depends on them. Then they are business managers. Their positions tend to spend more time on interpersonal skills, such as team management and development, as well as using conceptual skills to work with board managers and provide analysis of the development, implementation, and improvement of organizational strategies. The job responsibilities of managers are mainly to implement and implement the decision-making made by the directors of the company. The next step is to supervise and coordinate the grassroots managers or front-line employees to effectively complete the organizational work. Some enterprises are "pyramid" structures, corporate directors are at the top of the organizational structure, grassroots employees are at the bottom, and managers are the link between the board and the grassroots. Managers account for a significant portion of the company, managing the company's day-to-day work and organizing corporate production activities, interpreting and executing organizational strategies, and creating an efficient work environment to achieve the organization's ultimate goals.

\subsection{Management Department Leadership}

From a business perspective, leadership includes individual leadership and organizational competencies. Individual leadership is a measurable personal trait that determines individual job performance in a given environment and atmosphere. Organizational leadership is the combination of a range of knowledge and skills that a team or group of people demonstrates in their work to achieve an effective organizational goal. Leadership includes systemic, relevant and curability characteristics. The characteristic structure of leadership involves individual characteristics, behavioral characteristics and working situation conditions [3].

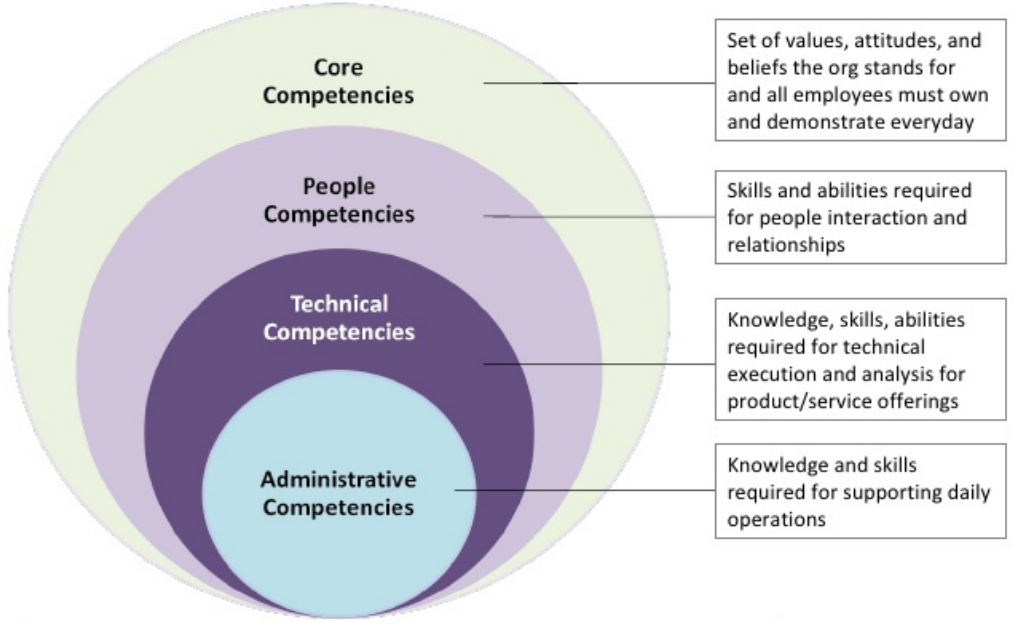

Fig.1 Corporate leadership components 


\subsection{Management department execution}

Execution is often the ability to use resources effectively and implement strategic intent to achieve organizational strategic goals. Execution is composed of the willingness, ability and degree of accomplishing the organization strategy or task. The efficient transformation of organizational strategy, development planning and goals into benefits and results is the main embodiment of execution. Execution can be explored at all levels, such as the individual, team and enterprise levels [4]. At the individual level, executive power is mainly reflected in the ability to handle affairs. For example, the executive performance of senior executives is mainly reflected in organizational management and control capabilities, but mainly in the ability to achieve work indicators; the combat effectiveness at the team level is the satisfaction of strategic decision-making into results. The integration of precision and speed is the embodiment of the overall combat effectiveness, competitiveness and cohesion of the organization team.

\section{SMEs' leadership and execution data research}

\subsection{Data collection}

According to the statistical principle, when the sample of the sample analysis is selected, the confidence calculation formula is expressed as follows:

$$
z=\frac{E}{\sqrt{\frac{p q}{n}}}
$$

According to the above formula, the peer-to-peer operation is performed to obtain a formula for calculating the number of samples:

$$
n=\frac{z^{2} p q}{E^{2}}
$$

Among them:

$\mathrm{p}=$ sample percentage

$\mathrm{q}=1-\mathrm{p}$

$\mathrm{z}=$ confidence

$\mathrm{E}=$ acceptable error

$\mathrm{n}=$ sample size

The sample percentage (p) in the above formula means that the accuracy is affected by the percentage of the sample selection option. In this paper, the rigor and science are strictly followed in the selection of samples. The confidence level is 1.96, the acceptable error is 0.025 , and under the condition of $95 \%$ confidence level, according to the above formula, the different sample percentages required for this study are obtained. The numbers of job samples under the conditions, different sample values are obtained according to different sample percentages.

\subsection{Quantitative processing}

This article uses Microsoft Excel data processing functions to quantify, Excel data processing function is the most effective and accurate quantitative processing application in word processing software. The first is to select the category of managerial responsibilities, including educational background, personal traits and management work experience. The most complicated is the 
individual traits, which comprehensively summarizes 17 skill characteristics, and each skill is more Integration of responsibilities requirements [5]. After the classification of the above categories, the quantitative processing of the sample data was started. Through the application of Count, Sum and other functions in Excel, combined with the application of the skill database and keywords in the influencing factors, all the positions were obtained. The frequency of skills required. The overall sample raw data is obtained through a combination of multiple inspections and manual inspections.

\section{Management department leadership and execution model building}

\subsection{Education background}

This paper conducts a chi-square test analysis on the academic requirements of managerial positions in different types of enterprises, and verifies whether the educational background has differences in different types of enterprises. Before the data is analyzed, the original factors are first subjected to data casualization and assignment. The principle of analysis is the check-in method of the contingency table. First, the quantity table is weighted, and then the cross-tab analysis in the descriptive statistical method of the SPSS analysis software is used. The result is shown in Table 1 by the chi-square test.

Tab.1 Chi-square test results of company type and education

\begin{tabular}{|l|l|l|l|}
\hline \multicolumn{4}{|c|}{ Chi-Square Tests } \\
\hline & Value & df & Asymp. Sig. (2-sided) \\
\hline Pearson Chi-Square & $47.513^{\mathrm{a}}$ & 4 & 0.000 \\
\hline Likelihood Ratio & 52.246 & 4 & 0.000 \\
\hline Linear-by-Linear & 43.568 & 1 & 0.000 \\
\hline Association & 746 & \multicolumn{3}{|l}{} \\
\hline a. 0 cells (0.00\%)have expected count less than 5. The minimum expected count is 12.23
\end{tabular}

The significant value of the chi-square test is 0.000 , which is far less than 0.05 , indicating that the significance is particularly high. According to the chi-square test principle, the original hypothesis is unreasonable, that is, the manager's academic requirements are particularly strong under different company types. Difference [6]. It can be concluded that the more the company is larger, the more important it is for the manager's educational background, and the higher the manager's academic qualifications.

\subsection{Management work experience}

According to the analysis of manager's management work experience requirements for different types of enterprises, this paper also adopts the chi-square test to explore whether there are differences in the requirements of management experience under different types of enterprises. In the process of data analysis and processing, this paper assigns small and medium-sized enterprise types to 1, 2 and 3 respectively, and management work experience of 1-2 years, 3-5 years and 5 years are assigned 1, 2 and 3. The analysis results obtained by the chi-square test in SPSS.20 are shown in Table 2. 
Tab. 2 Chi-square test results of company type and education

\begin{tabular}{|c|c|c|c|c|c|c|}
\hline \multicolumn{7}{|c|}{ Company type, management work experience confabulation } \\
\hline & & & \multicolumn{3}{|c|}{ Management work experience } & \multirow{2}{*}{ Total } \\
\hline & & & 1 & 2 & 3 & \\
\hline \multirow{6}{*}{ Type of company } & \multirow{2}{*}{1} & Count & 57 & 125 & 35 & 217 \\
\hline & & Expected Count & 52.4 & 121.8 & 42.8 & 217.0 \\
\hline & \multirow{2}{*}{2} & Count & 53 & 123 & 34 & 210 \\
\hline & & Expected Count & 50.7 & 117.8 & 41.4 & 210.0 \\
\hline & \multirow{2}{*}{3} & Count & 48 & 119 & 60 & 227 \\
\hline & & Expected Count & 54.8 & 127.4 & 44.8 & 227.0 \\
\hline \multirow{2}{*}{\multicolumn{2}{|c|}{ Total }} & Count & 158 & 367 & 129 & 654 \\
\hline & & Expected Count & 158.0 & 367.0 & 129.0 & 654.0 \\
\hline
\end{tabular}

The result analysis shows that the analysis ideas and methods of management work experience are the same as the educational background. The Sig. value of the chi-square test is 0.038 , which is less than 0.05 . There are significant differences in the results, that is, the managerial experience requirements of managers are different under different company types. Strong difference. It can be concluded that the more the company is, the more management experience is required for the manager, and the longer the management experience is required.

\subsection{Personal traits}

The skill requirements of this article's personal traits are obtained through research sample extraction. Through the subsidization and collation of all job responsibilities, seventeen factors are obtained: communication coordination ability, professional theoretical knowledge, familiarity with work flow, analysis and judgment ability, teamwork Spirit, professionalism, team leadership, ethical quality, responsibility, resilience, execution, logical thinking, insight, affinity, initiative and cohesion. The research idea is to explore the distribution trend and importance of 17 individual personality skills under different types of enterprises.

Tab. 3 Wilco rank sum test results

\begin{tabular}{|c|c|c|c|}
\hline \multicolumn{4}{|c|}{ Test Statistics $^{\mathrm{a}}$} \\
\hline $\mathrm{Z}$ & mid-min & Max-min & Max-mid \\
\hline Asymp. Sig. (2-sided) & $-274 \mathrm{~b}$ & -1.7640 & -4270 \\
\hline
\end{tabular}

\section{Enhance departmental leadership and execution measures}

\subsection{Enhance departmental decision-making mechanisms}

Improve the business process of administrative work, standardize and scientifically transform the administrative execution process, ensure the timeliness of implementation, and implement the executive execution process with sensitive execution command elements, implement strict and scientific implementation monitoring methods, and establish leadership-oriented learning. The system promotes the application of new tools and new technologies in the implementation work. The learning system is also an institutional framework for ensuring that the executive leadership has a vision of the times that is in harmony with social progress and can promote the generation of 
learning leadership. Third, at the level of civil servant personnel management system, the executive execution activities of leaders are inseparable from the task assignment and implementation of grassroots employees. Therefore, an efficient and fair personnel management system is also an institutional guarantee to ensure the implementation of administrative leaders in the process of decision-making. Employing people and tasks to distribute talents [7].

\subsection{Enhance the personal ability and literacy of leaders}

Leaders should put the most common ideas on the improvement of morality. They must be dedicated and moral in this function, communicate sincerely, be proactive, and do things in place. Especially as a government executive leader, we must continue to cultivate and improve political literacy. To establish a model of political thought for the society and to be a model group of the socialist core value system and the moral system. The improvement of administrative business ability should focus on the procedural work of administrative institutions, promote the optimization of administrative affairs work processes and links, and improve administrative efficiency; economic management ability is the key point that administrative agencies should emphasize in the market economy environment. The business capabilities include market observation ability, judgment ability and expected growth ability and benefit concept; finally, the improvement of social management ability, should emphasize the social public interest orientation, and enhance administrative execution activities based on the grasp of public resources and information advantages. Resolve social contradictions and promote social welfare.

\subsection{Enhance the art of leaders}

Leadership art is the first choice problem. A good leader should be able to develop strengths and avoid weaknesses in the selection of talents, quantitative scientific selection criteria and reference standards. Talent allocation also needs to be done by people, because they use people and match people to avoid Use the emotions in the process of talents, do not interfere with the selection of talents through personal emotional channels; at the same time, the leadership art will also seek scientific and efficient management skills, management work should be strict and strict, strict, and appropriate to create a relaxed and happy The working atmosphere should be encouraged in the management process. It is important not to suppress subordinates and frequent corrections. It is necessary to control personnel dynamics in the communication of subordinates and avoid the emergence of Gangtok and small teams. Regarding the authorization work, the executive leaders should follow the principle of appropriateness, and should dare to decentralize without over-distributing power. They must trust their subordinates, give them enough space to let go, encourage innovation, and also carry out strict supervision and information control. Actions and actions within the scope of authority to timely suppress bad execution activities.

\section{Conclusion}

This research firstly obtained the requirements of managers' academic background and management work experience for all types of small and medium-sized enterprises. After analysis, it was found that the larger the enterprise scale, the higher the academic background and management work experience. Secondly, in terms of the overall distribution of managers' personal traits, there are 17 individual skill traits with increasing importance. The big companies and Chinese companies, Chinese companies and small companies do not have differences in the overall distribution, while large companies and small companies There are significant differences in this requirement. From the single skill requirement analysis and research, the ability of small and medium-sized enterprises 
to communicate and coordinate management personnel, professional theoretical knowledge, familiarity with work processes, team leadership, learning innovation ability and cohesion are almost the same, but for professionalism, logical thinking, In terms of skills such as execution and insight, the larger the company type, the higher the requirements. Among the more special personal traits, the requirements of teamwork for large enterprises are much higher than those for small and medium-sized enterprises. In terms of the ethical quality of managers, small companies require higher requirements than medium-sized companies.

\section{References}

[1] Wang Xuemin, Niu Shuzhen. How to Improve the Leadership of SMEs Based on the "GE Leadership Model". China Securities and Futures, Vol. 2(2010) No.12, p. 48-49.

[2] Liu Zhai, Wang Yu, Chen Yan. The Impact of SME Entrepreneurship Leadership on Entrepreneurial Performance_-The Moderating Role of Enterprise Development Stage. Science \& Technology Progress and Policy, Vol. 7(2016) No.33, p. 101-107.

[3] Zhang Zheng. Ways for SMEs to Improve Leadership. Manager, Vol. 1(2012) No.23, p. 66-68.

[4] Wang Wei, Wu Zhongyuan. On the Development of Leadership of SME Operators in China. Modern Marketing (Late), Vol. 3(2013) No.18, p. 9-14.

[5] Wu Wei. Reflections on the Construction of SMEs' Executive Ability. Modern Economic Information, Vol. 11(2011) No.17 p. 44-48.

[6] Wu Yanli, Xing Xiufeng. Research on the Reasons for the Lack of Executive Ability of SMEs and Countermeasures. Business Economics, Vol. 4(2009) No.5, p. 66-69.

[7] Song Yousheng. Several Important Factors to Improve the Executive Ability of Small and Medium Enterprises. Journal of Tianjin Manager College, Vol. 1(2007) No.15, p. 225-228. 